Удк 581.543+581.192.2+547.978.1+581.522.4+582.675.34

\title{
СЕЗОННАЯ И ВОЗРАСТНАЯ ДИНАМИКА СОДЕРЖАНИЯ БЕРБЕРИНА В ИНТРОДУЦИРОВАННОМ ВЕRВERIS SIBIRICA PALL.
}

\author{
() И.В. Нечепуренко ${ }^{* 1}$, Н.И. Комарова ${ }^{1}$, О.Н. Потёмкин ${ }^{2}$, Н.Ф. Салахутдинов \\ ${ }^{1}$ Новосибирский институт органической химии им. Н.Н. Ворожцова СО РАН, \\ пр. акад. Лаврентьева, 9, Новосибирск, 630090 (Россия), \\ e-mailniv@nioch.nsc.ru \\ ${ }^{2}$ Центральный сибирский ботанический сад СО РАН, ул. Золотодолинская, \\ 101, Новосибирск, 630090 (Россия), e-mail: 1964o@mail.ru
}

В течение трех вегетативных сезонов методом ВЭЖХ изучена динамика содержания изохинолинового алкалоида берберина в корнях и надземной части интродуцированного в условиях ЦСБС СО РАН барбариса сибирского различных возрастных состояний. Показано, что корни б. сибирского содержат в 3-5 раз больше берберина, чем стебли. Содержание берберина в корнях возраста 7 лет колеблется в течение сезона незначительно, среднее значение составляет $1,10 \%$, максимальное содержание берберина было найдено в июле $(1,16 \pm 0,03 \%)$. Корни возраста 3 года содержат меньшее количество берберина. Из образца интродуцированных корней с содержанием $0,95 \%$ берберина был препаративно выделен берберинхлорид с выходом 0,62\%, что является показателем, близким для получения берберинхлорида из дикорастущих корней.

Ключевые слова: берберин, Berberis sibirica, динамика алкалоидов, интродукция, ВЭЖХ.

\section{Введение}

Использование возобновляемого растительного сырья широко применяется для получения биологически активных соединений. Однако постоянно усиливающаяся антропогенная нагрузка на биологические сообщества приводит к уничтожению растительного многообразия и безвозвратной потере уникального природного генофонда. На фоне современного сокращения ареалов и уничтожения популяций, расширение ассортимента ресурсных растений путем их интродукции позволяет комплексно решить ряд актуальных проблем, стоящих перед человечеством. Успешная интродукция растений, помимо решения биологических задач (таких как способность расти и давать потомство), предполагает выяснение вопроса - способно ли интродуцированное растение образовывать требуемый метаболит в непривычных для него условиях существования. Физиология и биохимия интродуцентов в значительной степени зависят от условий выращивания и ухода; известны случаи, когда растения при интродукции не накапливают алкалоиды $[1,2]$.

Изохинолиновый алкалоид берберин является ценным веществом, обладающим противомикробной, антибактериальной, гипохолестеринемической активностью [3, 4]. Берберин выделяли в виде хлорида (рис. 1) или сульфата из растений родов барбарис (Berberis), бархат (Phellodendron), хохлатка (Corydalis),

Нечепуренко Иван Васильевич - научный сотрудник, кандидат химических наук, тел.: (383) 330-88-70, e-mail: niv@ nioch.nsc.ru

Комарова Нина Ивановна - ведущий инженер, тел.: (383) 330-88-70, e-mail: komar@ nioch.nsc.ru Потёмкин Олег Николаевич - заведующий лабораторией дендрологии, старший научный сотрудник, кандидат биологических наук, тел.: (383) 330-27-63, e-mail: 1964o@ mail.ru Салахутдинов Нариман Фаридович - руководитель Отдела медицинской химии, доктор химических наук, тел.: (383) 330-97-33, e-mail: anvar@ nioch.nsc.ru желтокорень (Hydrastis). На территории бывшего СССР ботаническими садами введены в культуру 45 видов барбариса. Из растений, произрастающих на территории России и содержащих берберин, наиболее широко распространены растения рода барбарис: в европейской части - б. обыкновенный (Berberis vulgaris L.) и в азиатской части - б. сибирский (Berberis sibirica Pall.), виды являются близкими и многими авторами не различаются. Б. сибирский -

\footnotetext{
* Автор, ведущий переписку
} 
<smiles></smiles>

Рис. 1. Берберинхлорид сильно ветвистый колючий кустарник высотой до 1,5 м, с ползу чими, одревесневающими корневищами. Ксерофит, олиготроф, светолюбив. Произрастает в Саянах, Республике Алтай (Россия), а также в Средней Азии, Монголии [5].

Б. сибирский успешно интродуцирован в Центральном Сибирском ботаническом саду (ЦСБС), несмотря на то, что природно-климатические условия интродукции и естественного ареала произрастания б. сибирского отличаются довольно значительно [6]. В природе б. сибирский произрастает на скалах в областях рс сухим и довольно жарким климатом. Арборетум ЦСБС расположен в окрестностях Новосибирска, Россия (географические координаты 83.104 Е, 54.821 N), высота 114-130 м. над ур.м., продолжительность вегетационного периода (Т выше $\left.+5^{\circ} \mathrm{C}^{\circ}\right)-158$ дней, длительность безморозного периода - 120 дней. Несмотря на суровую длительную зиму, интродуцированный б. сибирский не подмерзал, регулярно плодоносил с 6 лет. Интродуцированный б. сибирский растет хорошо и может быть использован как растение для городского озеленения. Однако остается нерешенным вопрос - сколько берберина содержится в интродуцированном б. сибирском и может ли он заменить растения из природных популяций при производстве берберина?

При изучении химического состава б. сибирского из Казахстана [7] и из Монголии [8], из корней, побегов и листьев выделено 14 алкалоидов, основным является берберин. Однако данные по изучению динамики накопления берберина в растениях рода Барбарис и зависимости его содержания от условий произрастания довольно фрагментарны. Для B. oblonga (Казахстан) найдено, что содержание берберина в корнях максимально в конце вегетации (1,22\%), а в молодых побегах - в начале фазы цветения $(0,30 \%)$ [9]. Было показано, что для B. koreana максимальное содержание берберина в корнях достигается в октябре (вероятно, в конце вегетационного сезона) и составляет 1,32\% [10]. Для молодых побегов B. integerrima и B. nummularia (Узбекистан) содержание берберина максимально также в фазу цветения - 0,24 и 0,29\%, соответственно [11]. В работе [12] показано, что при увеличении высоты произрастания барбариса B. asiatica (Западные Гималаи) с 1200 до 2450 м над ур.м., содержание берберина в корнях падает с 3,2 до 1,6\%.

Нами поставлена задача: определить оптимальную продолжительность выращивания растительного сырья б. сибирского для получения берберинхлорида, для чего необходимо изучить динамику содержания берберина в различных органах барбариса сибирского, интродуцированного в ЦСБС (Новосибирск, Россия) в зависимости от возраста растений и фазы сбора.

\section{Экспериментальная часть}

Растительный материал. По 2-3 растения интродуцированных популяций б. сибирского возраста 3, 7, 12-20 лет были собраны в различные периоды вегетации (май, июнь, июль, август 2009-2011 г) в арборетуме ЦСБС СО РАН, Новосибирск, Россия (83.104 Е, 54.821 N, 114-130 м н.у.м.). Дикорастущие растения барбариса сибирского возраста 12-20 лет были собраны в Онгудайском районе Республики Алтай (Россия) в июле 2009 г. Образцы высушивались при комнатной температуре, разделялись на стебли (без листьев) и подземную часть, измельчались. Образцы растений были заложены в гербарий ЦСБС СО РАН под номерами NS-332-57, NS-332-85, NS -332-110, NS-332-197, NS-332-44, NS-332-1145.

Аналитическая экстракиия. Экстракция проводилась для четырех параллельных проб. Точную навеску (1 г) измельченных органов барбариса сибирского (корни или стебли) экстрагировали 12 мл $70 \%$ водного спирта при кипячении в течение 2 ч, горячий экстракт фильтровали. Экстракцию повторяли дважды с 10 мл 70\% водного спирта. Остаток после экстракции промывали 70\% водным спиртом, экстракты объединяли, доводили до метки в мерной колбе ( $\mathrm{V}=50$ мл). Полученный экстракт барбариса сибирского центрифугировали (10 000 об/мин, 5 мин) и использовали для непосредственного определения содержания берберина в пересчете на берберинхлорид методом ВЭЖХ.

ВЭЖХ-определение. Содержание берберина определяли на жидкостном микроколоночном хроматографе «Милихром А-02» (Эконова, Россия). Для хроматографического разделения использовали колонку с ProntoSIL-120-5-C18 AQ (5 мкм, 2×75 мм) при температуре $35^{\circ} \mathrm{C}$, давлении 30-36 атм, потоке 
150 мкл/мин. Объем инъекции пробы - 2 мкл. Проводили градиентное элюирование в системе растворителей А (0,1\% раствор трифторуксусной кислоты в воде) и Б (метанол), от $100 \%$ А до $100 \%$ Б за 25 мин с одновременной многоволновой детекцией на пяти длинах волн (210, 230, 260, 300, 346 нм).

В качестве стандарта использовали образец берберинхлорида моногидрата, выделенный из б. сибирского природных популяций по методике [13] после тройной перекристаллизации. Вещество имело чистоту по ВЭЖХ более 99\%, удовлетворительный элементный анализ и не содержало примесей в спектре ЯМР ${ }^{1}$ Н. В режиме остановленного потока определяли максимумы поглощения в УФ-спектре стандартного образца берберинхлорида моногидрата (230, 266, 346 нм). Для количественного определения берберина использовали значения оптической плотности на длине волны 346 нм. Используя стандартный образец берберинхлорида моногидрата, построили калибровочную прямую путем измерения при четырех различных концентрациях, для каждой концентрации раствора хроматографическое определение проводили трижды, площади пиков усредняли. Калибровочная прямая описывается уравнением (1) и показывает хорошую линейную регрессию $(\mathrm{r} 2=0,9974)$.

$$
S=73,959 \cdot m+0,149
$$

где $\mathrm{m}$ - масса берберина, нанесенного на хроматографическую колонку (мкг), и $\mathrm{S}$ - площадь пика, м.о.е.

На практике для вычисления массы вещества могут быть использованы округленные значения коэффициентов в уравнении (1), и значение приведенной весовой экстинкции моногидрата берберинхлорида

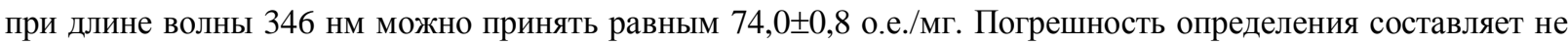
более 5\% (относит.). Диапазон рабочих концентраций: верхняя граница - 2,0 мг/мл; предел обнаружения 0,3 мкг/мл.

Гомогенность и идентичность пика берберина в экстрактах растений подтверждали сравнением спектральных отношений в различных точках хроматографического пика и сравнением со временем удерживания и спектральными отношениями стандартного образца берберинхлорида моногидрата. Для каждой пробы экстракта ВЭЖХ определение площади пика берберина проводили дважды, полученное значение усредняли. Расчет содержания берберина (в пересчете на берберинхлорид) проводили согласно уравнению:

$$
\text { Содержание, } \%=\frac{S \cdot V}{74,0 \cdot V_{s} \cdot m} \cdot 100 \% \text {, }
$$

где $\mathrm{S}$ - усредненная площадь пика, о.е.; V - общий объем экстракта (50 мл = 50000 мкл); 74,0 - приведенная весовая экстинкция стандартного образца берберинхлорида (о.е./мг); $\mathrm{V}_{\mathrm{s}}$ - объем пробы, вводимый для анализа (2 мкл); m - масса растительного образца (1000 мг).

Статистический анализ. Для трех-четырех сходящихся результатов определения содержания берберина вычисляли среднее арифметическое и стандартное отклонение $S_{x}$ (уравнение (3)).

$$
S_{x}=\sqrt{\frac{\sum\left(\Delta x_{i}\right)^{2}}{n \cdot(n-1)}},
$$

где $\mathrm{n}$ - число измерений.

Для проверки значимости различий между найденными значениями содержания берберина в различных образцах использовали $t$-тест Стьюдента [14]. Значения критерия $t$ рассчитывали по уравнению:

$$
t=\frac{\left|\bar{x}_{1}-\bar{x}_{2}\right|}{\sqrt{\frac{S_{1}^{2}}{n_{1}}+\frac{S_{2}^{2}}{n_{2}}}},
$$

где $\bar{x}_{1}, \bar{x}_{2}$ - содержание берберина в сравниваемых образцах; $S_{1}, S_{2}$ - стандартные отклонения $\bar{x}_{1}, \bar{x}_{2} ; n_{1}, n_{2}$ - число измерений. 
Когда $\mathrm{n}_{1}=\mathrm{n}_{2}=4, t=2 \cdot \frac{\left|\bar{x}_{1}-\bar{x}_{2}\right|}{\sqrt{S_{1}^{2}+S_{2}^{2}}}$. Если рассчитанное значение $t>S t\left(\mathrm{P} ; \mathrm{n}_{1}+\mathrm{n}_{2}-2\right)$, то сравниваемые значения имеют значимое различие. При $\mathrm{P}=0,99, \mathrm{n}_{1}=\mathrm{n}_{2}=4, S t=3,71$.

Для объединенной выборки значение среднего рассчитывали как среднее арифметическое значение величин; стандартное отклонение рассчитывали по уравнению:

$$
S^{2}=\frac{\sum_{i}\left(n_{i}-1\right) \cdot S_{i}^{2}}{\sum_{i}\left(n_{i}-1\right)}
$$

если $\mathrm{i}=3, \mathrm{n}_{1}=\mathrm{n}_{2}=\mathrm{n}_{3}=4$, то $S^{2}=\frac{\sum S_{i}^{2}}{3}$.

\section{Обсуждение результатов}

Морфологически для корневой системы барбариса сибирского нами выделено несколько основных стадий развития. При виргинальной фазе (возраст до 4-х лет) растение имеет небольшой корень, много мелких корешков, при этом главный стержневой корень начинает обособляться к концу 2-го года развития. При переходе в генеративное состояние (от 4-х до 8-ми лет) растение имеет выраженную стержневую корневую систему, центральный корень увеличивается в размерах, растет количество боковых корешков. Максимального размера корень достигает к 8-ми годам. При этом в центре начинается отмирание, боковые стебли деревенеют. Было собрано по 2-3 растения каждого возраста трижды за сезон - в начале вегетации (май), в середине сезона (фаза плодоношения, июль) и в конце вегетативного сезона (октябрь 2009 г.). Для каждого возрастного состояния проводили определение содержания берберина в корнях и побегах растений.

Экстракция растительных образцов проводилась путем трехкратного кипячения в 70\% этаноле [13]. Экстракты фильтровали, объединяли, доводили до точного объема в мерной колбе и анализировали методом ВЭЖХ. В данных условиях разделения берберин выходит гомогенным пиком со временем удерживания 1660-1694 мкл (пик, отмеченный знаком *, на рисунке 2). Количественное определение содержания берберина в пересчете на берберинхлорид моногидрат проводили путем сравнения площади пика на хроматограмме с площадью пика стандартного образца берберинхлорида моногидрата, для которого приве-

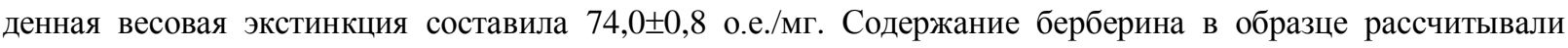
в процентах от веса сухого растения.

Результаты определения содержания берберина в образцах корней и стеблей интродуцированного барбариса сибирского сбора 2009 г. приведены в таблице 1. Сравнение данных показывает, что содержание берберина в корнях превышает содержание берберина в стеблях в 3-5 раз. В середине сезона имеется максимум накопления берберина и в корнях, и в стеблях. При изучении содержания берберина в побегах найдено, что берберин практически не содержится в свежеотросших концах веток $(0,02 \%)$; в толстых побегах, окрашенных на изломе в желтый цвет, найдено 0,18\% берберина (точка «Июль 2009, Побеги, Природная 12 - 20»). Проведено сравнение содержания берберина в корнях б. сибирского, произрастающего в природных условиях (Онгудайский район Республики Алтай) и интродуцированного в условиях ЦСБС. Содержание берберина в дикорастущих взрослых корнях (12-20 лет) несколько выше, чем в интродуцированных $(1,42$ и 1,21\%, соответственно; точки «Июль 2009, Корни, Природная 12 - 20» и «Интродукция, 12 - 20»), но различие не очень значительное. С другой стороны, корни интродуцированного барбариса имеют большее относительное содержание берберина, что может облегчить препаративное выделение берберина (см. рис. 2 a, б).

Данные таблицы 1 показывают, что выделение берберина из надземной части б. сибирского является нетехнологичным, так как они содержат низкое количество берберина и большое количество других компонентов. Соответственно, для получения берберина хлорида необходима заготовка корней б. сибирского, несмотря на то, что это приводит к уничтожению растения. Необходимо ответить на вопрос - насколько долго следует выращивать б. сибирский для достижения максимального выхода берберина? Представляется, что поскольку содержание берберина в старых корнях (более 8 лет) не превышает значительно содержание берберина в корнях возраста 6-7 лет, нецелесообразно выращивать барбарис более 6-8-ми лет. 


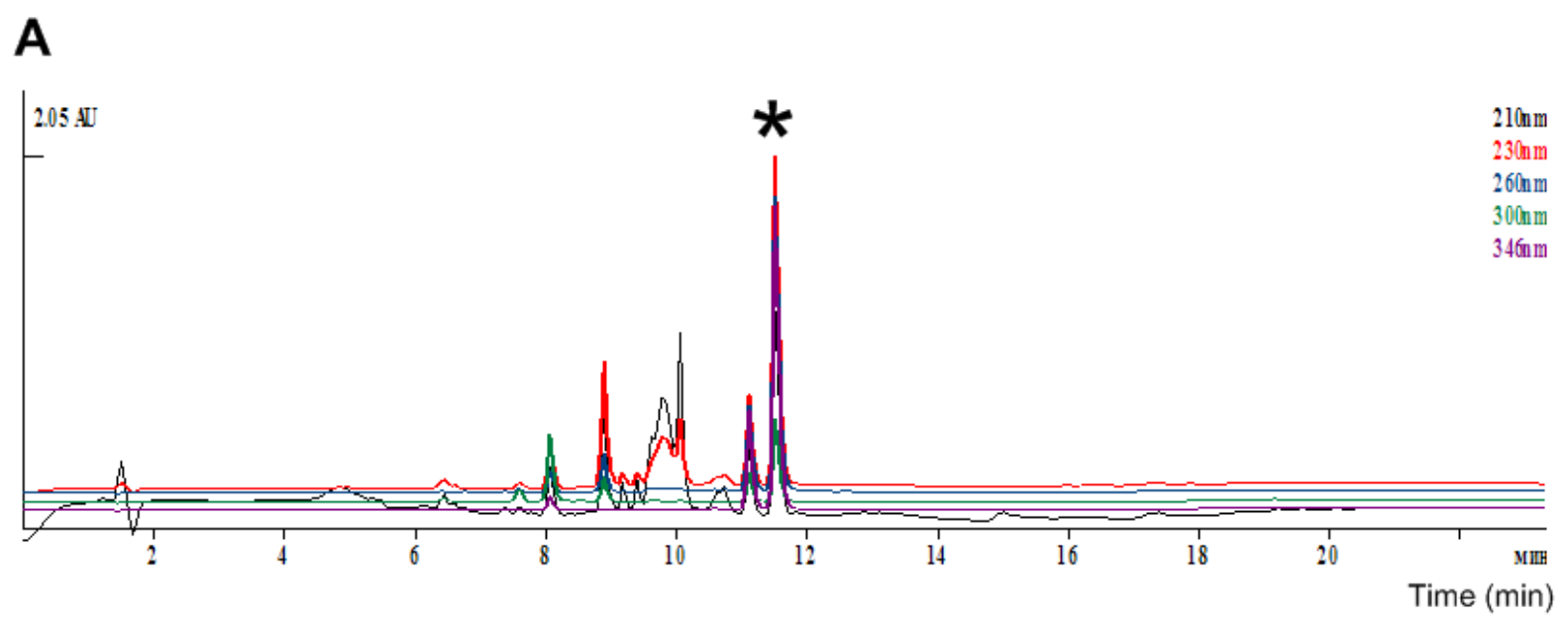

\section{Б}

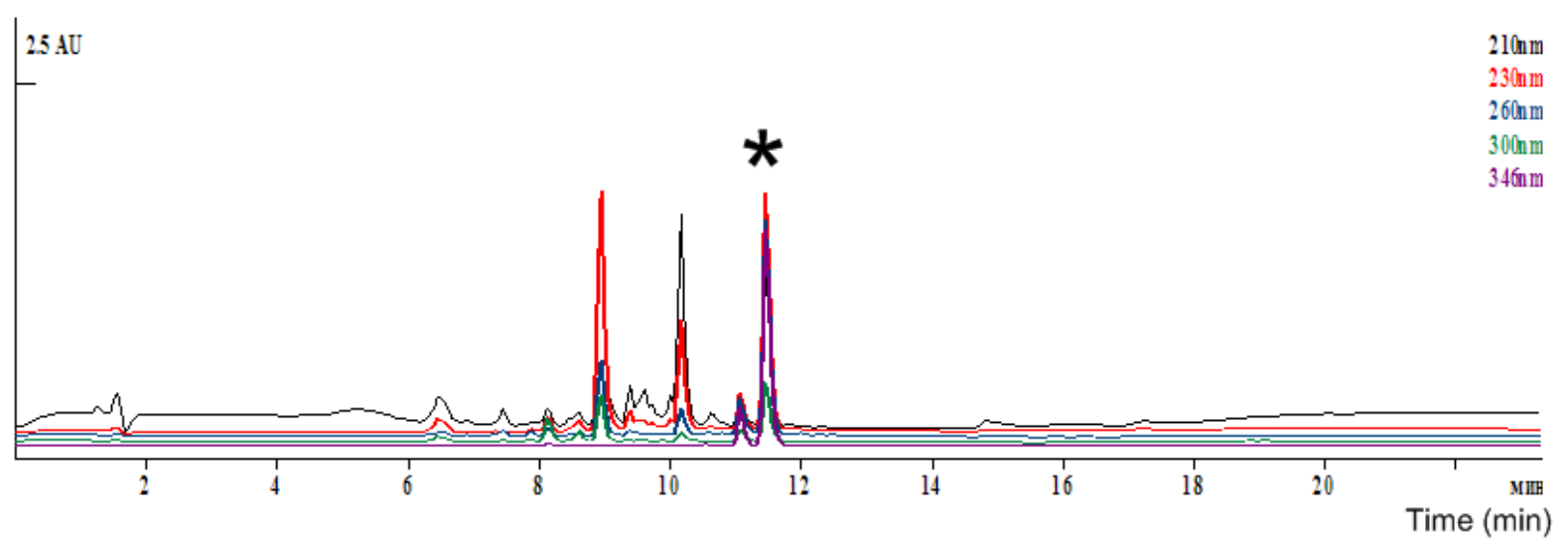

Рис. 2. Хроматограмма ВЭЖХ экстракта корней б. сибирского: а) интродуцированной популяции, б) природной популяции. Пик берберина отмечен знаком (*)

Таблица 1. Содержание берберина, процент от сухого веса, в корнях и побегах интродуцированного и природного б. сибирского, 2009 г.

\begin{tabular}{c|c|c|c|c|c|c}
\hline Популяция, & \multicolumn{2}{|c|}{ Май 2009 } & \multicolumn{2}{c|}{ Июль 2009 } & \multicolumn{2}{c}{ Октябрь 2009 } \\
\cline { 2 - 7 } возраст, лет & Корни & Побеги & Корни & Побеги & Корни & Побеги \\
\hline $\begin{array}{c}\text { Интродукция, } \\
2-4\end{array}$ & $0,54 \pm 0,01$ & $0,23 \pm 0,01$ & $0,60 \pm 0,02$ & $0,29 \pm 0,03$ & $0,66 \pm 0,02$ & $0,20 \pm 0,03$ \\
$\begin{array}{c}\text { Интродукция, } \\
6-7\end{array}$ & $0,83 \pm 0,03$ & $0,17 \pm 0,02$ & $1,13 \pm 0,05$ & $0,14 \pm 0,04$ & $0,67 \pm 0,01$ & $0,03 \pm 0,02$ \\
$\begin{array}{c}\text { Интродукция, } \\
12-20\end{array}$ & $0,63 \pm 0,02$ & $0,19 \pm 0,02$ & $1,21 \pm 0,01$ & $0,29 \pm 0,02$ & $0,31 \pm 0,01$ & $0,037 \pm 0,004$ \\
$\begin{array}{c}\text { Природная, } \\
12-20\end{array}$ & & & $1,42 \pm 0,02$ & $0,18 \pm 0,01^{\mathrm{a}}$ & & \\
\hline
\end{tabular}

Примечания: ${ }^{\text {с }}$ старые побеги; ${ }^{6}$ молодые побеги.

Нами проведено дополнительное исследование корней интродуцированного б. сибирского, с целью уточнения динамики накопления берберина для растений возрастных состояний 3 и 7 лет, собранных в 2010 и 2011 гг., результаты приведены в таблице 2. Для каждой даты сбора проведено статистическое сравнение содержания берберина в корнях трех- и семилетних растений с использованием $t$-теста Стьюдента (уравнение 4) [14]. Результаты статистического анализа показывают, что можно говорить определенно о значимом различии содержания берберина в популяциях трех- и семилетних растений. 
Таблица 2. Содержание берберина, процент от сухого веса, в корнях интродуцированного б. сибирского, 2010 и 2011 гг.

\begin{tabular}{c|c|c|c|c|c|c|c|c|c}
\hline $\begin{array}{c}\text { Возраст, } \\
\text { лет }\end{array}$ & 31.05 .2010 & 01.07 .2010 & 20.07 .2010 & 07.08 .2010 & 29.08 .2010 & 30.05 .2011 & 28.06 .2011 & 28.07 .2011 & 31.08 .2011 \\
\hline 3 & $1,49 \pm 0,03$ & $0,86 \pm 0,04$ & $0,98 \pm 0,04$ & $0,78 \pm 0,02$ & $0,64 \pm 0,01$ & $0,66 \pm 0,02$ & $0,97 \pm 0,03$ & $1,05 \pm 0,04$ & $1,22 \pm 0,01$ \\
7 & $1,17 \pm 0,04$ & $1,17 \pm 0,01$ & $1,15 \pm 0,02$ & $0,95 \pm 0,02$ & $1,14 \pm 0,01$ & $1,18 \pm 0,04$ & $1,06 \pm 0,01$ & $1,20 \pm 0,03$ & $0,92 \pm 0,03$ \\
\hline
\end{tabular}

Данные в таблицах 1 и 2 показывают, что в корнях барбариса возраста 7 лет содержание берберина находится на довольно большом уровне и колеблется незначительно как в течение вегетационного сезона, так и в различных годах. Можно заключить, что наилучшим временем для сбора корней возраста 7 лет является интервал 20-30 июля, который соответствует точкам «Июль 2009 г.» (табл. 1), «20.07.2010» и 28.07.2011 (табл. 2). Согласно тесту по $t$-критерию Стьюдента, эти точки (значения $1,13 \pm 0,05 ; 1,15 \pm 0,02$; $1,20 \pm 0,03$ соответственно) принадлежат одной выборке (не имеют значимых отличий). При объединении этих выборок мы получаем усредненное значение содержания берберина в июле и его стандартное откло-

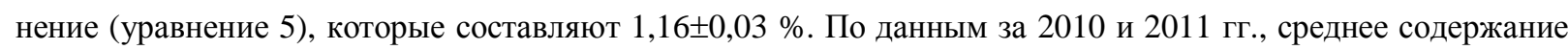
берберина в течение всего сезона вегетации составило $1,10 \%$, крайние отклонения от среднего значения составили $+0,10$ и $-0,18 \%$. Это означает, что корни возраста 7 лет можно собирать не только в оптимальное время, и при этом содержание берберина будет лишь не намного ниже.

Для корней барбариса возраста 3 года картина содержания берберина является более сложной. В 2010 и 2011 гг. динамика накопления берберина не совпадает. Должны быть проведены дополнительные исследования для того, чтобы определить - обусловлены ли значения в точках «31.05.2010» $(1,49 \%)$ и 31.08.2011 (1,22\%) (табл. 2) особенностями климатических условий данных сезонов или другими факторами. Если не рассматривать эти точки, то видно, что в целом содержание берберина в корнях возраста 3 года меньше, чем в корнях возраста 7 лет.

Данные за 2009 и 2011 гг. для трехлетних корней показывают увеличение содержания берберина в конце вегетативного сезона, что противоположно данным по семилетним корням, имеющим максимум в середине сезона. Следует отметить, что согласно литературным данным, для барбарисов, произрастающих в более жарких регионах (возраст неизвестен), максимальное содержание берберина в корнях наблюдалось в конце вегетативного сезона $[9,10]$. С другой стороны, динамика накопления берберина в популяциях б. сибирского, произрастающих в Республике Алтай (Россия) (как наиболее близких к интродуцированным в Новосибирске), не изучалась. Очевидно, что с переходом от виргинильного (v) состояния растения (3 года) к генеративному $(\mathrm{g} 1, \mathrm{~g} 2)$ (7 лет) характер биосинтеза вторичных метаболитов может меняться, и динамика накопления берберина может также измениться. Вероятно также, наблюдаемые различия в динамике накопления берберина между семилетними растениями, интродуцированными в ЦСБС, и природными популяциями, описанными в литературе, обусловлены различием природных и климатических условий.

При сравнении трех- и семилетних корней можно видеть, что их сырой вес составляет 20-30 г для трехлетних корней и около 70-100 г для семилетних. При механизированной обработке на $1 \mathrm{~m}^{2}$ целесообразно выращивание 6-8 корней барбариса, что может дать урожайность около 4.8 тонны на гектар для трехлетних корней (собрано 2 урожая), или около 8 тонн с гектара для семилетних корней (собран один урожай). Следовательно, выращивание семилетних корней является более предпочтительным для производства берберина.

Необходимо было также сопоставить содержание берберина в корнях, определенное по ВЭЖХ, и выход продукта (берберинхлорида) при выделении. Была приготовлена объединенная проба интродуцированных корней барбариса, для которой аналитическое определение дает содержание берберина $0,95 \pm 0,03 \%$. При экстракции образца и дальнейшей его обработке по методике [13] было получен берберинхлорид с выходом $0,62 \%$. Для сравнения, при экстракции корней дикорастущего б. сибирского (содержание берберина $1,42 \pm 0,02 \%$, см. табл. 1, точка «Июль 2009 г., Корни, Природная $12-20 »)$, берберинхлорид был получен с выходом $0,71 \%$. Если принять урожайность семилетних корней б. сибирского равной 8 т/га, сухой вес корней - около половины сырого веса, и выход берберина равным $0,62 \%$, то можно получить около 25 кг берберинхлорида моногидрата с 1 га. 


\section{Заключение}

Результаты работы показывают, что интродуцированный б. сибирский является эффективным источником для получения алкалоида берберина. Он хорошо произрастает в холодном климате и достигает оптимального веса корней к возрасту 6-8 лет. Содержание берберина в таких корнях варьируется незначительно в течение сезона вегетации и составляет в среднем $1,10 \%$, максимальное содержание берберина было найдено в июле $(1,16 \pm 0,03 \%)$. Корни более молодого возраста (3-4 года) имеют намного меньшую массу и содержат меньшее количество берберина. Использование интродуцированнных популяций барбариса для производства биологически активных соединений может помочь в сохранении природных популяций растений.

\section{Список литературь}

1. Шлыков Г.Н. Интродукция и акклиматизация растений, М., 1963. 488 с.

2. Петровская-Баранова Т.П. Физиология адаптации и интродукция растений, М., 1983. 152 с.

3. Нечепуренко И.В., Салахутдинов Н.Ф., Толстиков Г.А. Берберин: химия и биологическая активность // Химия в интересах устойчивого развития. 2010. Т. 18, №1. С. 1-23.

4. Tillhon M., Ortiz L.M.G., Lombardi P., Scovassi A.I., Berberine: New perspectives for old remedies // Biochemical Pharmacology. 2012. Vol. 84. Pp. 1260-1267.

5. Малышева Л.И., Пешковой Г.А. Флора Сибири. Новосибирск, 1994. Т. 7. С. 9.

6. Встовская Т.Н., Коропачинский И.Ю. Древесные растения центрального сибирского ботанического сада. Новосибирск, 2005. 234 с.

7. Каримов А., Левкович М.Г., Абдуллаев Н.Д., Шакиров Р. Алкалоиды Berberis. XXIX. Исследование алкалоидов Berberis sibirica // Химия природных соединений. 1993. №3. С. 424-428.

8. Istatkova R., Philipov S., Tuleva P., Amgalan S., Samdan J., Dangaa S., Alkaloids from Mongolian species Berberis sibirica Pall. // Comptes Rendus de l'Academie Bulgare des Sciences. 2007. Vol. 60. Pp. 1177-1182.

9. Каримов А., Шакиров Р.Ш. Алкалоиды Berberis. XIV. Динамика накопления алкалоидов в Berberis oblonga // Химия природных соединений. 1992. №5. С. 597-598.

10. Yoo S.J., Lee K.B., Kwak J.H., Studies on the seasonal variation of berberine contents in Berberis koreana // Saengyak Hakhoechi. 1986. Vol. 17. Pp. 123-128.

11. Каримов А., Мелибоев С., Олимов В., Шакиров Р. Алкалоиды Berberis. ХХХ. Динамика накопления алкалоидов Berberis integerrima и B. nuтmularia // Химия природных соединений. 1993. №3. С. 472-473.

12. Andola H.Ch., Gaira K.S., Rawal R.S., Rawat M.S.M., Bhatt I.D., Habitat-Dependent Variations in Berberine Content of Berberis asiatica Roxb. ex. DC. in Kumaon, Western Himalaya // Chemistry \& Biodiversity. 2010. Vol. 7. Pp. 415-420.

13. Патент 2423992 (РФ). Способ получения пакистанамина и берберина хлорида из Berberis sibirica / И.В. Нечепуренко, М.П. Половинка, Н.И. Комарова, Н.Ф. Салахутдинов, Г.А. Толстиков // БИ. 2011. №20.

14. Дёрффель К. Статистика в аналитической химии. М., 1994. 268 с. 
Nechepurenko I.V. ${ }^{{ }^{*}}$, Komarova N.I. ${ }^{1}$, Potemkin O.N. ${ }^{2}$, Salakhutdinov N.F. ${ }^{l}$ SEASONAL AND AGE VARIATIONS OF BERBERINE CONTENT IN INTRODUCED BERBERIS SIBIRICA PALL.

${ }^{I}$ N.N. Vorozhtzov Novosibirskii Institute of Organic Chemistry of the Siberian Branch of Russian Academy of Sciences, Lavrent'eva ave., 9, Novosibirsk, 630090 (Russia),e-mail: niv@nioch.nsc.ru

${ }^{2}$ Central Siberian Botanical Garden of the Siberian Branch of Russian Academy of Sciences, Zolotodolinskay str., 101, Novosibirsk, 630090 (Russia)

The content of isoquinoline alkaloid berberine was studied by means of HPLC in the roots and the above-ground part of introduced Berberis sibirica Pall. of various ages collected during different periods of three vegetative seasons. The roots contain 3-5 times more berberine than the stems. The content of berberine in 7-year-old roots varies slightly during the season; its mean value was $1.10 \%$ and maximum content was found in July $(1,16 \pm 0.03 \%)$. The roots of the age of 3 years contain fewer berberine. Berberine chloride has been preparatively isolated from the introduced roots containing $0,95 \%$ of berberine; the yield was $0,62 \%$, which is close to the value typical for obtaining berberine chloride from wild roots.

Keywords: berberine; Berberis sibirica; alkaloids dynamics; introduction; HPLC.

\section{References}

1. Shlykov G.N. Introdyktsiya i akklimatizatsiya rastenii. [Introduction and akklimatization of plants]. Moscow, 1963. 488 p. (in Russ.).

2. Petrovskaya-Baranova T.P. Fisiologiya adaptatsii i introdyktsii rastenii. [Physiology of adaptation and introduction of plants]. Moscow, 1983. 152 p. (in Russ.).

3. Nechepurenko I.V., Salakhutdinov N.F., Tolstikov G.A. Khimiya v Interesakh Ustoichivogo Razvitiya, 2010, vol. 18, pp. 1-23. (in Russ.).

4. Tillhon M., Ortiz L.M.G., Lombardi P., Scovassi A.I. Biochemical Pharmacology, 2012, vol. 84, pp. 1260-1267. (in Russ.).

5. Malysheva L.I., Peshkovoii G.A. Flora Sibiri. [The flora of Siberia]. Novosibirsk, 1994, vol. 7, pp. 9-10.

6. Vstovskaya T.N., Koropachinskii I.Y. Drevesnye rasteniya tsentralnogo sibirskogo botanicheskogo sada. [Wood plants in Central Siberian Botanical Garden]. Novosibirsk, 2005. 234 p.

7. Karimov A., Levkovich M.G., Abdullaev N.D., Shakirov R. Chemistry of Natural Compounds, 1993, vol. 29, pp. 361-364. (Khimiya prirodnykh soedinenii, 1993, no. 3, pp. 424-428. (in Russ.).).

8. Istatkova R., Philipov S., Tuleva P., Amgalan S., Samdan J., Dangaa S. Comptes Rendus de l'Academie Bulgare des Sciences, 2007, vol. 60, pp. 1177-1182.

9. Karimov A., Shakirov R.S. Chemistry of Natural Compounds, 1992, vol. 28, pp. 524-525. (Khimiya prirodnykh soedinenii, 1992, no. 5, pp. 597-596. (in Russ.).).

10. Yoo S.J., Lee K.B., Kwak J.H. Saengyak Hakhoechi, 1986, vol. 17, pp. 123-128.

11. Karimov A., Meliboev S., Olimov V., Shakirov R. Chemistry of Natural Compounds, 1993, vol. 29, pp. 412-413. (Khimiya prirodnykh soedinenii, 1993, no. 3, pp. 472-473. (in Russ.).).

12. Andola H.C., Gaira K.S., Rawal R.S., Rawat M.S.M., Bhatt I.D. Habitat-Dependent Variations in Berberine Content of Berberis asiatica Roxb. ex. DC. in Kumaon, Western Himalaya. Chemistry \& Biodiversity, 2010, vol. 7, pp. 415-420.

13. Patent 2423992 (RU). 2011.

14. Doerffel K. Statistika v analyticheskoi chimii. [Statistik in der analytischen Chemie]. Moscow, 1994. 268 p. (in Russ.).

\footnotetext{
* Corresponding author.
} 